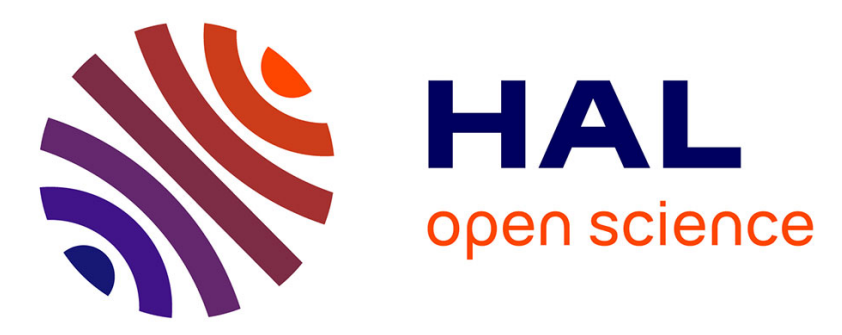

\title{
Comparison of experimental results and finite element simulation of strain localization scheme under cyclic loading
}

C Gérard, Franck N'Guyen, Nikolay Osipov, Georges Cailletaud, Michel Bornert, Daniel Caldemaison

\section{To cite this version:}

C Gérard, Franck N'Guyen, Nikolay Osipov, Georges Cailletaud, Michel Bornert, et al.. Comparison of experimental results and finite element simulation of strain localization scheme under cyclic loading. Computational Materials Science, 2009, 46, pp.755-760. 10.1016/j.commatsci.2009.04.037 . hal00423616

\section{HAL Id: hal-00423616 https://hal.science/hal-00423616}

Submitted on 12 Oct 2009

HAL is a multi-disciplinary open access archive for the deposit and dissemination of scientific research documents, whether they are published or not. The documents may come from teaching and research institutions in France or abroad, or from public or private research centers.
L'archive ouverte pluridisciplinaire HAL, est destinée au dépôt et à la diffusion de documents scientifiques de niveau recherche, publiés ou non, émanant des établissements d'enseignement et de recherche français ou étrangers, des laboratoires publics ou privés. 


\title{
Comparison of experimental results and Finite element simulation of strain localization scheme under cyclic loading
}

\author{
C. Gérard ${ }^{* a, b, c}$ F. N'Guyen ${ }^{\text {a }}$ N. Osipov ${ }^{\text {a }}$ G. Cailletaud ${ }^{\text {a }}$ M. Bornert ${ }^{b}$ D. Caldemaison ${ }^{\text {b }}$

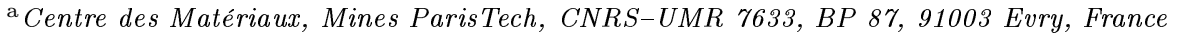 \\ b Laboratoire de Mécanique des Solides, Ecole Polytechnique, CNRS-UMR 7649, 91128 Palaiseau Cedex, France \\ ${ }^{\mathrm{c}}$ Laboratoire des Propriétés Mécaniques et Thermodynamiques des Matériaux, Université Paris 13, CNRS-UPR 9001, 93430 Villetaneuse, \\ France
}

\begin{abstract}
The plastic behaviour of FCC materials is studied under cyclic tensile-compression loading at room temperature. The material is an oxygen-free high conductivity copper. The purpose of the work is to model the onset of plasticity, then the cycle by cycle evolution of the localized strain, at grain scale and at mesoscopic scale.

A polycrystalline aggregate taking into account the material microstructure is developped to perform finite element simulations corresponding to the experiments. Finite element calculations are carried out on this mesh, using a constitutive law which takes into account the crystallographic orientation of each grain. An analysis of the localisation scheme is performed at different steps of the cyclic loading.
\end{abstract}

Key words: Micromechanics, Field Measurement, Crystal Plasticity, Finite Element

\section{Introduction}

Localisation of strain into deformation bands is a known and well-studied phenomenon in polycrystalline materials in the framework of finite strains (see for instance [1], [2]). A few studies dating back to the 90's [3], [4], [5], highlighted the existence, at the scale of the microstructure and already at low levels of plastic deformation, of such localisation bands, oriented at more or less $\pm 45^{\circ}$ with respect to the tensile axis. The material under study were two-phase elastoplastic materials $(\mathrm{Cu} / \mathrm{Fe}, \mathrm{Ag} / \mathrm{Fe}$ or $\mathrm{Ag} / \mathrm{Ni}$ ). With the development of more accurate image correlation techniques applied to scanning electron microscope (SEM) images [6], [7], it could be shown that the onset of such bands is at a very early stage of plastic deformation [5], [8], and that such bands are also observed in single phase polycrystals such a zirconium alloys [9]. Their characteristic lengths can be evaluated by means of twopoint correlation functions [9] and may be significantly larger than the grain size [10] [11]. The overal orientation

Email address: celine.gerard@mat.ensmp.fr (C. Gérard*). of such bands is similar to that of the infinite bands that may occur in a homogeneous isotropic perfectly plastic material but their detailed location is clearly driven by the microstructure. While the paths of the bands can be reasonably well predicted in contrasted two-phase materials by means of simple image processing procedures [8], their prediction is much more tricky in single phase polycrystals, as maximal resolved shear stresses which drive plastic slip in grains depend on the local, strongly heterogeneous, stress. Much more sophisticated computational tools such a those presented here are then required. More recently, in 2007 and 2008, we extended this study of the appearance and the evolution of the strain localisation pattern to FCC single phase polycrystals and to cyclic tensile-compression loading paths at room temperature [12]. Local strain fields have been measured at several positions in the cycle, and over several cycles.

The work presented in this paper aims at reproducing the experimental measurements by means of finite elements models based on crystal plasticity constitutive relations in order to check their validity and to obtain more informa- 
tion on the phenomenon through an efficient dialog between simulation and experiment, especially at the beginning of the loading path where experimental measurements are too noisy for an accurate characterisation. As we refer to a real microstructure, the initial mandatory step of the approach is the generation of a virtual 3D aggregate of grains describing the microstructure of the specimen. Several studies [13], [14], [15], have established the clear dependence of the surface local strain fields on the local cristallographic texture and grain geometries at the surface of the sample, but also on the microstructure in the bulk underneath the surface under investigation. Generating a 3D microstructure by means of a translation of an electron back scattered diffraction (EBSD) map along its orthogonal direction does not provide sufficiently accurate results. A tridimensional realistic description of contrasted two-phase materials can obtained from microtomography [16], [17]. However, the extension of such procedures to polycrystals, by means of Diffraction Contrast Tomography [18] is still in an early stage of development. Alternatively, EBSD mapping and serial polishing operations [13], even if accurate, is a very long and destructive procedure. In such a context, several authors have developed intermediate solutions [19], [20], which associate the real EBSD surface map and a statistically consistent microstructure model under the surface. The various proposed procedures differ by the statistical model of the used 3D granular microstructure, which might be constrained Voronoï polyhedra generated from punctual germs [21], [22]) or from sets of ellipsoids [23], [24]. In the first part of this paper, the experimental procedure, based on digital image correlation techniques applied at the scale of the grains by means of an appropriate microgrid marking technique and a SEM-in situ cyclic tension-compression device, is shortly described [25]. Then, the 3D model of the microstructure geometry is detailed. Finally, the numerical results obtained by parallel finite element computations are compared to the experimental strain field and an analysis of the strain localisation scheme is performed at different steps of the loading path.

\section{Experimental procedure}

The material under investigation is a $14 \mathrm{~mm}$ thick sheet of hot rolled oxygen free high purity copper (OFHC). The loading path is a cyclic uniaxial tensile-compression test under prescribed overall axial strain. The mean axial strain is $-2 \%$ and ten cycles are carried out, with a strain amplitude of $2 \%$ (see figure 1 ).

The experiment is performed in the chamber of a Jeol JSM845 SEM by means of an in situ fatigue device with a

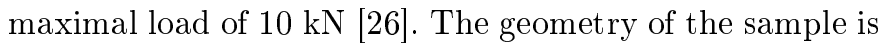
designed accordingly, with a rather short core zone in order to avoid buckling in compression (see figure 2). EBSD mapping and local strain field measurements are performed on a small flat polished area in the core zone, millimetric in size.

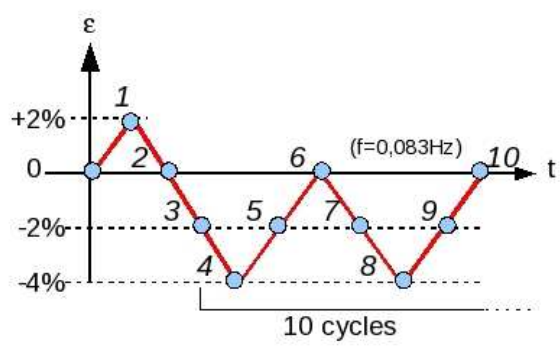

Fig. 1. a) Scheme describing the displacement imposed. The loading specifically numerically studied in the present paper come from the beginning to the step 6 .

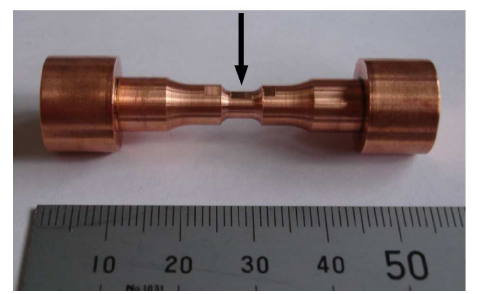

Fig. 2. Geometry of the samples used. The arrow indicate the flat surface where EBSD analysis and displacement field measurements are carried out

The area of interest is first delimited by 4 square gold marks, so that EBSD maps and strain field measurements can be carried out on the same zone and combined, following the guidelines of [27]. An EBSD map is recorded with a spatial resolution of one point per micrometer (see figure $4(\mathrm{a}))$. A $2-\mu m$-step gold microgrid is deposited by microelectrolithography [3] on the $500 \times 500 \mu m^{2}$ selected area. High definition $4 K \times 3 K$ pixels SEM digital images of the microgrids are recorded by means of an external scan generator and digitisation device, in the reference stage and the various deformation stages given by the blue dots in figure 1.

The displacement field is then obtained at each grid intersection (about 30000 positions) by image correlation techniques applied between the reference image and the deformed stages by means of the in-house correlation software CMV developped at LMS. It is based on the so-called zero-centred normalised cross-correlation coefficient, a local affine transformation in the correlation windows [28] and implements various procedures which allow to process images with a periodic contrast such as the one provided by microgrids [6].

This field is then differentiated to obtain the in-plane components of the deformation gradient and strain tensor over the zone covered by the microgrid, by means of the procedures described in [3]. The discrete derivation scheme used is such that the gage length for the local strain measurements is $4 \mu \mathrm{m}$.

During each cycle, five images are recorded: at $-4 \%,-2 \%$, $0,-2 \%$ and $-4 \%$ axial strain. Fig. 3 presents the relative strain field obtained for the step 6 , taking step 4 as reference. The results for the other cycles is not presented here due to lack of space but are available in [12], [29]. It is noted 


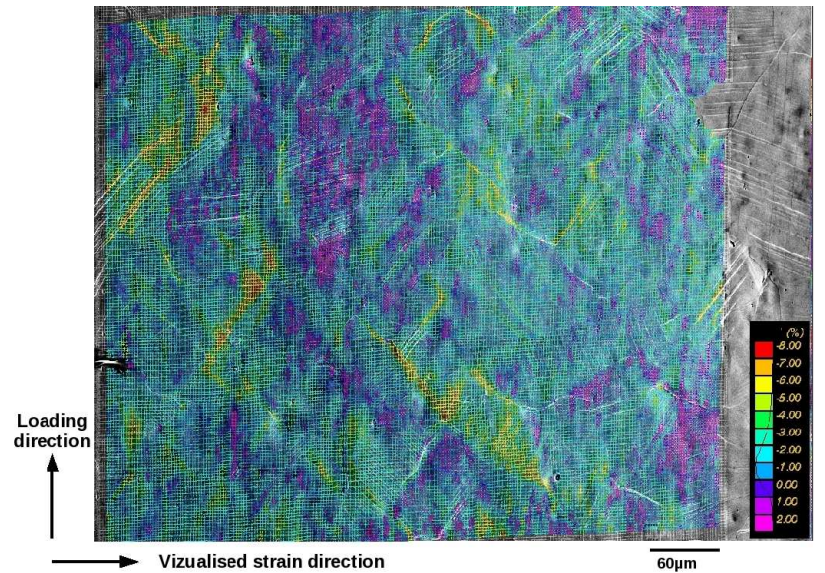

Fig. 3. Experimental relative strain field along tranverse component, on the step 6 , taking step 4 as reference.

that transverse strains are considered here, because this component is much less noisy than the others. The reason for that is related to the fact that the transverse direction is parallel to the lines of the SEM images. As a rather slow scanning speed is required to reduce the image noise (typically 50 microseconds per pixel) and a high image definition is required in order to investigate areas as representative as possible, the recording time of a single image is rather long (about 20 minutes). During such a long time, the electron beam can behave in an unstable manner and the sample may move slightly with respect to the SEM column. Both effects induce a relative motion of the scan lines on the sample which generate fictitious axial strains, which take the form of horizontal bands in the strain maps. This effect is much less perceptible in the transverse direction as the time between the acquisition of two pixels separated by a given distance along a line is about 3000 times shorter than the time between two pixels separated by the same distance along a column. Fictitious vertical deformation bands are thus much less intense on the transverse strain maps. A few of them can however be seen on the strain maps on figure 3 , but they are due to imperfections of digital to analog converter of the scan generator.

The main conclusions deduced were that the localisation bands appear during the first cycle, and remain the same during all the loading path. In each cycle, the intensity of localisation bands reaches its maximum at maximum load, then decreases and disappears more or less at minimum load. In the successive cycles, bands reappear allways at the same place, and are more and more intense. Unstrained areas remain undeformed during the whole loading path.

\section{Numerical simulation}

\subsection{Mesh and boundary conditions}

The analysis of EBSD maps (see figure 4(a)) highlights three main characteristics of the material considered in the study: a strong heterogeneity of grain sizes, lots of twins, and the noticeable presence of non-convex grains. The microstructure generation used is specially designed to preserve these three features, and keeps the EBSD map on the surface of the final aggregate.

This generation is driven in three times. First, the EBSD map is cleaned and analysed, separating twins from parent grains. Then, a tri-dimensional volume is generated on the based of Voronoï polyedra, constrained to fit the dispersion of grain sizes on each plan parallel to the EBSD map, as indicated below. Finally, the third dimension of grains in surface (meaning EBSD grains) is defined as also described here after.

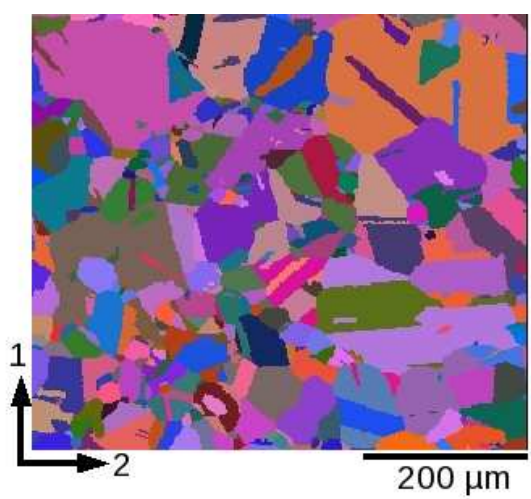

(a)

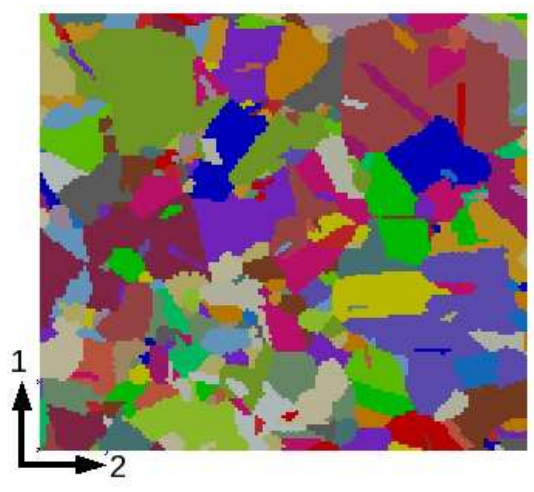

(b)

Fig. 4. a) EBSD map performed in the center of the core zone of the specimen. The size of the map is $500 \mu \mathrm{m} \times 440 \mu \mathrm{m}$; b) Surface of the numerical mesh corresponding to the EBSD map.

The EBSD map is cleaned and post-processed: the smallest grains, defined as those having a surface below 20 square pixels (i.e. 20 square micrometers) and those for which the orientation was left undetermined are deleted see figure 4(b). It is well-known that the tridimensionnal morphology of twins strongly differs from parent grain shape. Twins are then first detected, and treated separately from the rest of the microstructure in order to preserve their typical shape. Due to the presence of "twins in twins" (new twins produced in already twinned zones), crystallographic criteria were not considered, and twins were detected by their morphological characteristics: parallel borders are found by Radon transform, with a minimum threshold on lengthen- 
ing ratio, and removed.

In the next stage, the parent grains are represented by constrained Voronoï polyhedra. First, an aggregate of polyhedra is generated so that the average section of polyhedra by a plan parallel to the surface dedicated to EBSD is representative of the smallest grain area in the EBSD map. Next, polyhedra are merged with the closest neighbours in order to reach a microstructure with a grain section size distribution corresponding to EBSD measurement. The direction of merge propagation is left free. Consequently, grains obtained are morphologically non-convex. Finally, twins are modeled in this microstructure as subgrains with parallel slices of the parent grain which are cut in random directions.

Finally, the EBSD cleaned map is treated along the third direction. A procedure of grain growth orthogonally to the surface, with a probability of increasing or decreasing the section area, is applied. Twins are then introduced at the surface and prolongated in the volume following random directions. This layer of grains fit the aggregate generated. Figure 5 shows the result obtained: the final aggregate size is $500 \mu \mathrm{m} \times 540 \mu \mathrm{m} \times 220 \mu \mathrm{m}$. The total number of grains is 3710 .

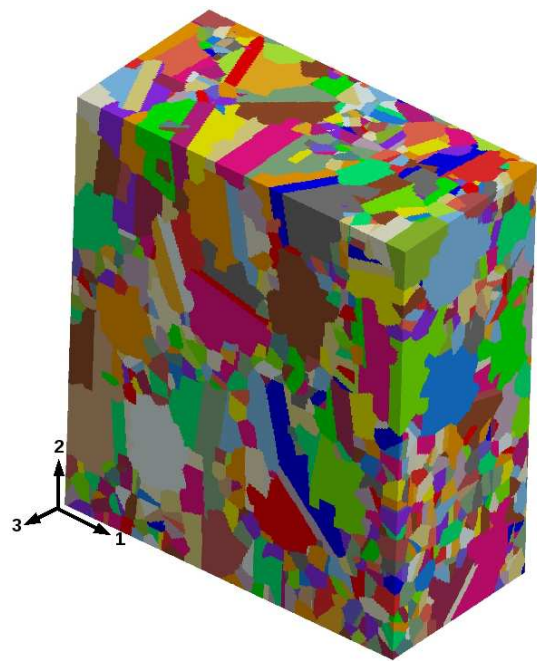

Fig. 5. Final microstructure obtained.

A regular mesh is used: it does not conform grain and twin boundaries. The $3 \mathrm{D}$ image is directly mapped on 1261260 multiphase elements.

Mixed boundary conditions are applied in order to simulate the onedimensional tensile-compression cyclic test. The displacement is imposed as indicated here: the normal displacement is equal to zero on 3 faces, $x_{1}=x_{1 \text { min }}$, $x_{2}=x_{2 \min }$ and $x_{3}=x_{3 \min }$. The normal displacement is prescribed in $x_{1}$ direction on the face $x_{1}=x_{1 \text { max }}$, and in direction $x_{2}$ on the face $x_{2}=x_{2 \max }$. The applied value is deduced from a simulation made with an uniform field model whose aggregate contains the same grains as the finite element mesh in terms of crystallographic orientation and volume fraction. This procedure is needed, since elastic strain is not negligible with respect to plastic strain, so that the apparent Poisson's ratio changes continunously from 0.33 to 0.5 . The face $x_{3}=x_{3 \max }$ is left free.

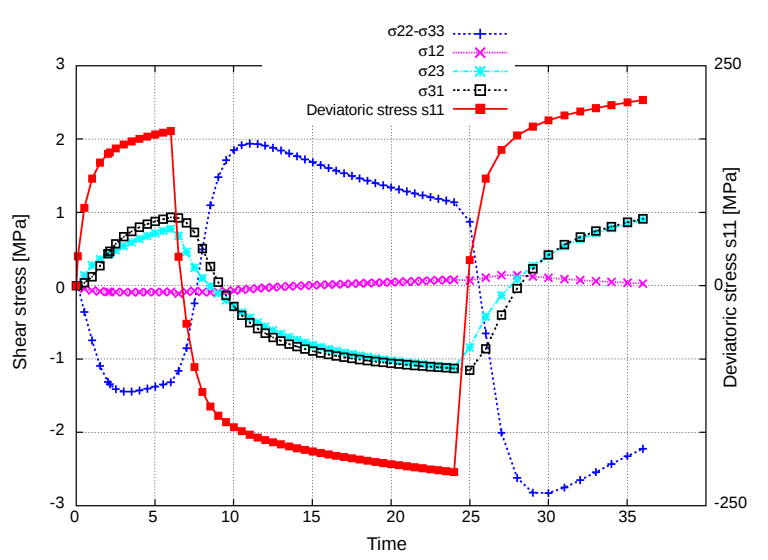

Fig. 6. Stresses for the four freedom degrees of shear and deviatoric stress.

\subsection{Constitutive equations}

The single crystal law used in this work was introduced in [30]. It was extensively used for the computations of polycrystalline aggregates (see for instance [31]). Only the main equations are reminded below. This model is presented in the framework of small strain. In the following, $\gamma^{s}$ is the viscoplastic shear on system $s$, and $v^{s}$ its accumulated value (the derivative of the second is the absolute value of the first one). Isotropic hardening is represented on each slip system by the variable $r^{s}$, and kinematic one by the variable $x^{s} . c$ and $d$ are material coefficients. The orientation tensor $\mathbf{m}_{\sim}^{s}$, that is computed for each system $s$ by a tensorial product of the normal to the slip plane $\underline{\mathbf{n}}^{s}$ and the slip direction $\underline{1}^{s}$, is used to evaluate the resolved shear stress $\tau^{s}$ and the viscoplastic strain rate tensor, $\underset{\dot{\varepsilon}}{p}$. Two material parameters, $K$ and $n$ represent the rate sensitivity, that is low; three parameters, $r_{0}, Q$ and $b$ (and the components $h_{r s}$ of the interaction matrix) represent isotropic hardening.

$$
\begin{gathered}
\dot{\gamma^{s}=}\left\lfloor\frac{\left\|\tau^{s}-x^{s}\right\|-r^{s}}{K}\right\rfloor^{n} \operatorname{sign}\left(\tau^{s}\right)=\dot{v}^{s} \operatorname{sign}\left(\tau^{s}\right), \\
x^{s}=c \alpha^{s} \quad \text { with } \quad \dot{\alpha}^{s}=\dot{\gamma}^{s}-d \dot{v}^{s} \alpha^{s}, \\
r^{s}=r_{0}+Q \sum h^{s r}\left(1-\exp \left(-b v^{r}\right)\right), \\
\underline{\sim}^{s}=\left(\underline{\mathbf{n}}^{s} \otimes \underline{\mathbf{l}}^{s}+\underline{\mathbf{l}}^{s} \otimes \underline{\mathbf{n}}^{s}\right) / 2 \\
\tau^{s}={\underset{\sim}{\mathbf{m}}}^{s}: \underset{\sim}{\sigma} \quad \dot{\sim}^{p}=\sum_{s} \dot{\gamma}^{s} \underline{\sim}^{s}
\end{gathered}
$$

Due to lack of space, the identification of material parameters is not presented here. The method of identification and the justification of such parameters, especially the hardening matrix is detailed in [32], and [12]. Table 1 gives the material parameters values. 


\begin{tabular}{|ccccccc|}
\hline$K\left(\right.$ MPa.( $\left.\left.s^{\frac{1}{n}}\right)\right)$ & $n$ & $r_{0}(\mathrm{MPa})$ & $Q(\mathrm{MPa})$ & $b$ & $\mathrm{c}(\mathrm{MPa})$ & $\mathrm{d}$ \\
8 & 20 & 15 & 4 & 12 & 32000 & 900 \\
\hline$h_{0}$ & $h_{1}$ & $h_{2}$ & $h_{3}$ & $h_{4}$ & $h_{5}$ & \\
1 & 1 & 0,2 & 90 & 3 & 2,5 & \\
\hline
\end{tabular}

Table 1 parameters of the single crystal model.

\section{Results and discussion}

Due to the simplified boundary conditions, the stress state is not a pure tension on the aggregate. Fig. 6 shows the history of the various stress components versus time. It can be observed that the shear components remain small: the maximum value is $1 / 100$ of the deviatoric stress $s_{11}$. Consequently, the loading imposed corresponds to an hydrostatic pressure added to the experimental tensile loading. Thus, only the elastic strain is modified. Fig. 7 and 8 presents strain fields, along transverse direction (22 component), saved at different time steps of the computation. The scheme of heterogeneity is different from the experimental one in the sense that localisation bands are not located at the same place. It has been observed in the past that local path is driven by the local microstructure. Although the microstructure is here statistically described along the third direction, the impact of the first layer of grains remains important enough to give a different scheme of strain heterogeneity. On the other hand, the strain levels are equivalent, and the morphology of bands seems to be comparable. This last point should be quantitatively investigated.

Fig. 8 shows the evolution of the transverse strain fields during one cycle, from the step 2 to 6 . The localisation pattern appears, becomes more intense, and then quite disappears. Undeformed zones remained non-strained. Experimental results are here clearly represented. Moreover, the comparison between the first vignette and the last one exhibits the beginning of a local ratchetting effect noticed on experimental investigations [12]. Indeed, the blue bands in the first one turn out to be yellow (with the same colour scale). As undeformed zones remain at the same level, it can be concluded that the phenomenon of ratchetting at a local scale results in the intensification of localization bands, and not in a spreading of the deformation.

The experimental analysis performed does not allow us to catch the very appearance of bands due to the accuracy limit under SEM related to the noise, as previously described. Figure 7 a presents the transverse strain field obtained in the finite element analysis for a $0.17 \%$ axial strain, at the onset of plastic flow. The corresponding point on the stress-strain loop is shown in Fig. 7b. It clearly appears that the localization pattern is already formed, with intense deformation bands at $\pm 45^{\circ}$ from the tensile axis.

\section{Conclusion}

A microstructure based on constrained Voronoï polyhedra is developped to statistically model the microstructure of an OFHC copper, taking into account the three main morphological characteristics noticed from EBSD maps: a strong heterogeneity of grain sizes, lots of twins, and the noticeable presence of non-convex grains. The EBSD map is truly described at the surface. It appears that this way of modelling the microstructure does not provide the exact strain field, but allows to describe, with a good agreement with experimental observation, its evolution under tension-compression cyclic loading. It clearly appears that the localisation pattern is set up just at the onset of plastic flow. Then the intensity of the localization increases and decreases with loading. A local phenomenon of ratchetting is noticed in the deformed band, while the undeformed zones remain at the same value during all the loading path, cycle after cycle.

\section{References}

* Now at: Department of Material Science, SN Bose National Centre for Basic Sciences, Block JD, Sector III, Salt Lake, Kolkata 700098, India.

[1] Yang S., Bacroix B., Int. J. Plast. 12 (1996) 1257-1285.

[2] Schroeter B. M., McDowell D. L., Int. J. Plast. 19 (2003) 13551376.

[3] Allais L., Bornert M., Bretheau T., Caldemaison D., Acta Met. 42 (1994) 3865-3880.

[4] Bornert M., PhD thesis, Ecole Polytechnique, France (1996).

[5] Doumalin P., PhD thesis, Ecole Polytechnique, France (2000).

[6] Doumalin P., Bornert M., Proc. of Interferometry in Speckle Light, Theory and Applications, P. Jacquot and J.M. Fournier Eds, Springer, Lausanne (2000), 67-74.

[7] Soppa E., Doumalin P., Binkele P., Weisendanger T., Bornert M., Schmauder S., Comput. Mat. Sc. 21 (2001) 261-275.

[8] Doumalin P., Bornert M., Soppa E., in Advances in mechanical behaviour, plasticity and damage 1 (2000).

[9] Doumalin P., Bornert M., Cr 'epin, J., M 'ecanique et Industries 4 (2003) 607-617.

[10] Elbachiri K., Doumalin P., Crepin J., Bornert M., Barberis P., Rebeyrolle V., Bretheau T., Proc. of Symposium on Zirconium in the Nuclear Industry, Sunriver, USA (2007).

[11] Dexet M., PhD thesis, Ecole Polytechnique, France (2006).

[12] Gérard, C., PhD thesis, University Paris XIII, France (2008).

[13] Musienko A., Tatschl A., Schmidegg K., Kolednik O., Pippan R., Cailletaud G., Acta Mat. 55 (2007) 4121-4136.

[14] Heripre E., PhD thesis, Ecole Polytechnique, France (2006).

[15] Zeghadi A., PhD thesis, Ecole des Mines de Paris, France (2005).

[16] Forest S., Jeulin D., Houdaigui F. El, Kanit T., Madi K., N'Guyen F., Zeghadi A., Boussuge M., Coll. Nat. MECAMAT, Approches multi-échelles en mécanique des matériaux, Aussois, France, (2006).

[17] Madi K., PhD thesis, Ecole des Mines de Paris, France (2006).

[18] King A., Johnson G., Ludwig W., Ed. by Pyzalla A.R., Borbely A., Degischer H.P., in Stress evaluation in materials using neutrons and synchrotron radiation, Materials science forum, 571-572 (2008) 207-212.

[19] Saylor D. M., Fridy J., El-Dasher B. S., Jung K. Y., Rollet A. D., Metal. and Mater. Trans. A 35A (2004) 1969-1979.

[20] Brahme A., Alvi M. H., Saylor D., Fridy J., Rollett A. D., Scripta Mat. 55 (2006) 75-80. 


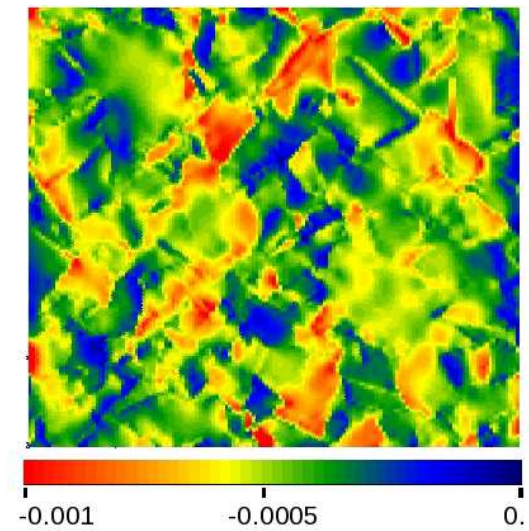

(a)

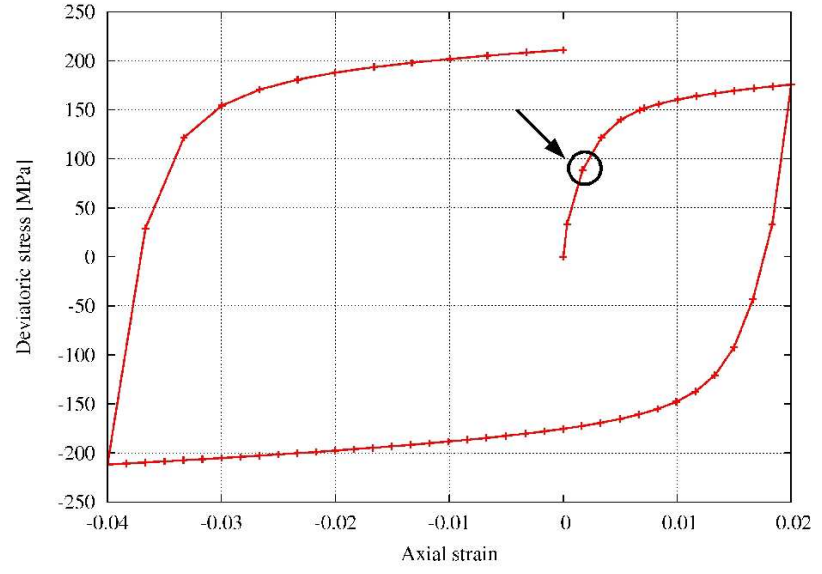

(b)

Fig. 7. a) Transverse strain field obtained by finite element computation, for an average axial strain of $0.17 \%$ b) Deviatoric stress-strain curve on the axial component. The arrow indicates the point corresponding to the strain field presented in a).
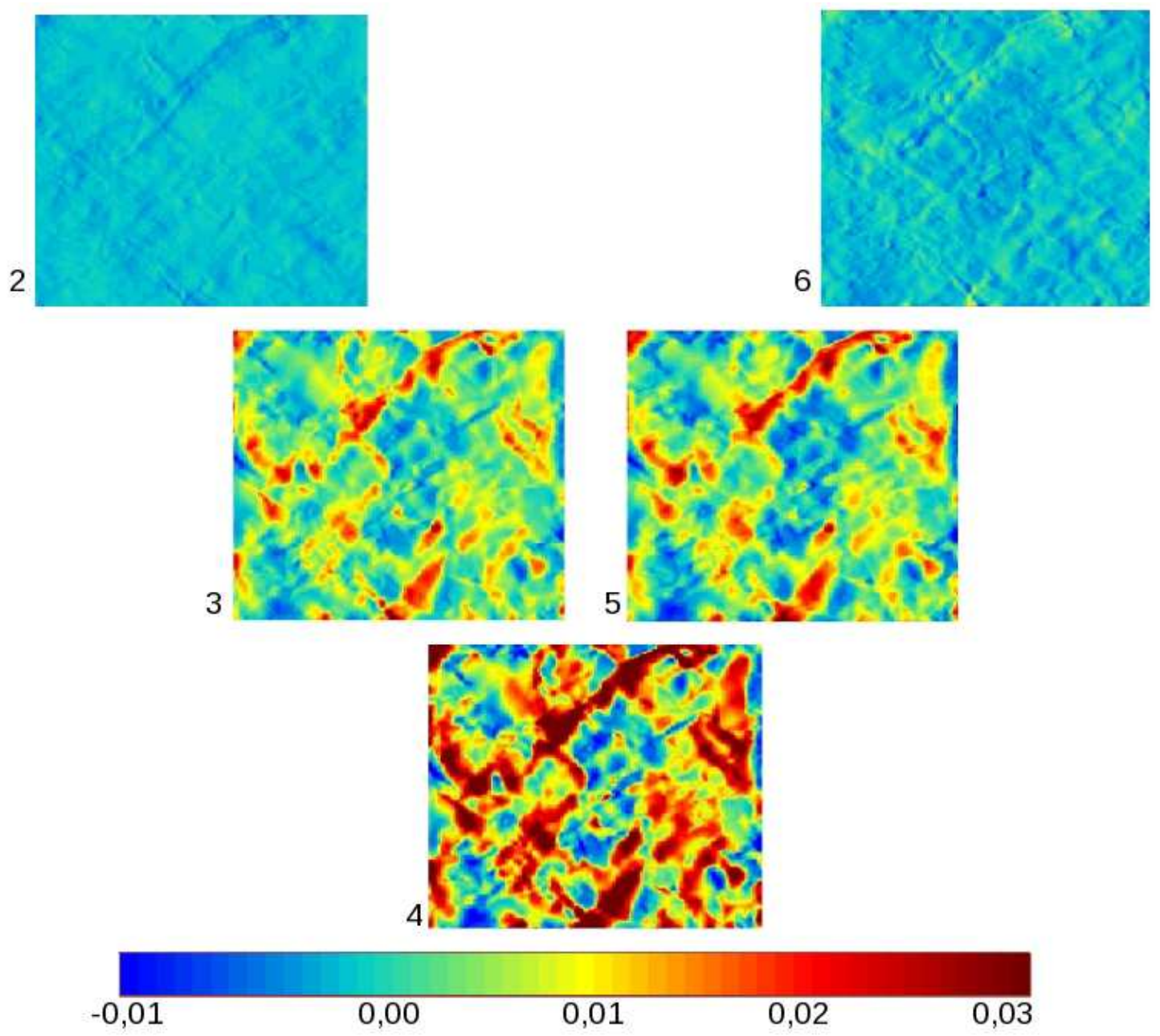

Fig. 8. Transverse strain fields obtained by fininte element analysis for steps 2 to 6 . 
[21] Mathieu JP., PhD thesis, Ecole Centrale de Paris, France (2006).

[22] Osipov N., Gourgues-Lorenzon AF., Marini B., Mounoury V., Nguyen F., Cailletaud G., Phil. Mag. 88 (2008) 3757-3777.

[23] Bilger N., PhD thesis, Ecole Polytechnique, France (2003).

[24] Saint-Pierre L., Héripré E., Dexet M., Crépin J., Bertolino G., Bilger N., Int. J. Plast. 24 (2008) 1516-1532

[25] Gerard C., Bornert M., Caldemaison D., Cailletaud G., submitted.

[26] Pinna C., Doquet V., Fatigue and Fracture of Engng Mat. and Struct. 22 (1999) 173-183.

[27] Heripre E., Dexet M., Crepin J., Gelebart L., Roos A., Bornert M., Caldemaison D., Int. J. of Plasticity 23 (2007) 1512-1539.

[28] Bornert M., Brémand F., Doumalin P., Dupré J.-C., Fazzini M., Grédiac M., Hild F., Mistou S., Molimard J., Orteu J.-J., Robert L., Surrel Y., Vacher P., Wattrisse B., Experimental Mechanics, (2009), to appear.

[29] Gérard C., Bacroix B., Bornert M., Brenner R., Cailletaud G., Caldemaison D., Chauveau T., Crépin J., Mounoury V., Leclercq S., Congrès Français de Mécanique, Grenoble, France (2007).

[30] Méric L., Cailletaud G., J. of Engng. Mat. Technol. 113 (1991) 171-182.

[31] Barbe F., Forest S., Cailletaud G., Int. J. Plast. 17 (2001) 537566.

[32] Gérard C., Bacroix B., Bornert M., Cailletaud G., Crépin J., Leclercq S., Comput. Mater. Sci. 45 (2009) 751-755. 